Originally published in Phenomenology and the Cognitive Sciences 2014, 1-15 [DOI 10.1007/s11097-0149366-y]. Please quote from published version.

\title{
SHADOWS OF CONSCIOUSNESS THE PROBLEM OF PHENOMENAL PROPERTIES
}

\author{
Jason M. Costanzo
}

\begin{abstract}
The aim of this essay is to show that phenomenal properties are contentless modes of appearances of representational properties. The essay initiates with examination of the first-person perspective of the conscious observer according to which a "reference to I" with respect to the observation of experience is determined. A distinction is then drawn between the conscious observer and experience as observed, according to which, three distinct modifications of experience are delineated. These modifications are then analyzed with respect to the content of experience and from this the ground of the distinction between phenomenal and representational properties is identified.
\end{abstract}

Keywords: phenomenal properties, representational properties, pre-reflective consciousness, reflectiveconsciousness, experience, mode, appearance

\section{Introduction: The Problem of Phenomenal Properties}

In general, we might say that each conscious state involves representation of a specific "intentional content" corresponding to that conscious state. A perception state involves representation of either a visualcontent or an auditory-content, and so on, for the five senses. Alternatively, corresponding to a belief state there is a belief-content, and to a pain state, a pain-content. So each conscious state has its corresponding intentional content and that content likewise corresponds to that conscious state. We cannot speak of a pain-content for a belief state, although we can speak of an association of states in the formation of more complex conscious states, for example, the feeling of guilt as a combination of belief and emotive feeling.

A distinction might furthermore be formulated between the intentional content of any conscious state and consciousness of the experience of that state, so that we might in turn speak of what it is like to experience (Nagel 1974), and this latter addition, commonly referred to as the subjective or "phenomenal character" of experience, may lead to the further supposition that, over and above the intentional content of experience, there is a specific "phenomenal content" pertaining to consciousness of what our experiences are like.

Within the philosophy of mind today, few would deny to experience its phenomenal character. In spite of this, there is hardly any agreement regarding the nature and relationship between the phenomenal and intentional content of experience. For some (i.e., "representationalists" such as Dretske 1995, Lycan 1996 and Tye 1995), there really is no fundamental difference between the two. The phenomenal content of experience is, at best, attributable to the way the intentional content is represented within experience. 
Among others (so-called "anti-materialists" such as Block 1995, Chalmers 1995 and Levine 2001), phenomenal character is the result of the way in which we are conscious of our experience and entails a distinct phenomenal content over and above intentional content. ${ }^{1}$

These two positions might likewise be considered in relation to the problem of phenomenal properties. So we might speak not only of intentional and phenomenal content but also of the properties of that content. A "representational property" would then be a property resulting from the intentional content of experience (Chalmers 2004), as a represented red-content or pain-content. On the other hand, a "phenomenal property" would be a property resulting from either the phenomenal content of experience (anti-materialism) or the way the representational property is represented (representationalism). In either case, the phenomenal property would express what the experience of red is like or what pain experience is like. ${ }^{2}$ So along with the content of experience, whereas anti-materialists affirm the separate instantiation of phenomenal properties within consciousness, representationalists deny their separate instantiation.

Within this essay, my primary aim will be to consider the phenomenal character of experience through examination of the problem of phenomenal properties. Indeed, this latter problem is ultimately tied to phenomenal character so that if an answer can be given to the question, "What is a phenomenal property?" then in the main we have likewise supplied an answer to the question, "What is phenomenal character?"

In addressing the question and problem of phenomenal properties, I shall likewise do so according to the following three suppositions: First, I affirm that there is something it is like to experience, thus upholding the phenomenal character of experience. Second, with representationalists, I reject the antimaterialist position that there is a separate phenomenal content over and above the intentional content of our experience. Third, I reject the representationalist position that phenomenal properties are the result of the way the intentional content is represented within experience and instead uphold the anti-materialist position that such properties are the result of the way in which we are conscious of our experience.

\footnotetext{
${ }^{1}$ I well recognize that the above distinction is a simplification of the varied and often complex positions and arguments offered by each side and likewise omits otherwise mediating points of view. For instance, we might further distinguish pure from impure representationalism (Chalmers 2004). My aim here, however, is not to offer a survey of the various positions on the issue, but instead, to offer a solution to the problem of phenomenal properties. From this latter perspective, the above distinction serves to establish the context according to which the solution to the problem of phenomenal properties here given may be understood and as such, need not necessarily apply, in all points, to those identified with such positions.

${ }^{2}$ We here restrict discussion of phenomenal properties to the perceptible properties of our experience. We can of course speak of what it is like to think, suppose, believe, and so on, and in such cases, we might identify an intentional content in relation to experience of one's own acts of consciousness, and alternatively, a phenomenal content in relation to consciousness of what the experience of one's own acts of consciousness is like. In spite of our focus upon perceptible properties, the solution here offered is understood to apply globally to the whole of consciousness of experience.
} 
From the above three suppositions, we obtain what might at first appear as a great hydra: phenomenal character, minus phenomenal content, coupled with the view that consciousness contributes something over and above the intentional content of our experience. Upon closer inspection, however, our solution to the problem of phenomenal properties involves what is here called property hylomorphism, which is to say, the view that consciousness and intentionality (representational experience) constitute an irreducible unity. In classical terms, intentional content contributes the matter of experience, consciousness the form. Through the union of matter and form, consciousness and intentionality, we then obtain a basis for discussion of the way in which we are conscious of our experience. As will likewise be seen, the peculiar form of consciousness, which is to say, what consciousness adds over and above experience, finds its principle through the "reference to I" with respect to the relationship between the conscious observer and experience as observed.

In what follows, I begin (section 2) with a number of arguments against the anti-materialist position that phenomenal properties are separate content-bearing properties and likewise against the representationalist position that phenomenal character is accountable solely on the basis of the intentional content of representational experience. Following this (section 3), I examine the relationship between consciousness and experience according to which a "reference to I" stands forth as an essential component in the discussion of our experience. The nature of pre-reflective and reflective consciousness is then considered, and through the latter, recognition of the relationship between the conscious observer and experience as observed follows. Further analysis (section 4) of this relationship yields three distinct modifications or modes of experience. In the first place, experience is modified in terms of the whole relation that holds between the observer and the observed (nominative). In the second place, experience is modified according to the reference of experience as observed, to the observer (dative). Finally, according to a third modification, experience is modified according to the observer's reference of experience to oneself as observer (genitive). Following this (section 5), we conclude that phenomenal properties are contentless appearances within consciousness as the result of a comparison formed for the same representational property according to distinct modifications of it within consciousness.

\section{Three Arguments Against the Instantiation and Representation of Phenomenal Properties}

As above noted, we uphold the view that there is something it is like to experience and that the phenomenal character of experience is attributable to consciousness of our experience. What must then be considered is first the question of why we ought to deny to phenomenal character any content over and above the intentional content of representational experience, and second, why representational experience itself cannot be the source of phenomenal character. In what follows, I offer three arguments. The first two arguments are targeted in the main at the anti-materialist position that consciousness involves instantiation of a separate phenomenal content over and above the representational content of experience. The third 
argument is targeted at the representationalist position that phenomenal properties are the result of the way in which the intentional content is represented within experience.

\section{The Knowledge Argument Against Property Dualism}

If as anti-materialists we assert that for every representational property $\mathrm{r}$ we have the separate instantiation within consciousness of a phenomenal property $p$ pertaining to what the experience of $r$ is like, then it seems that knowledge of $r$ is impossible. For knowing $r$ implies that $I$ also know $p$, which is to say, what it is like to know $r$, so that my knowledge of $r$ mutually entails $p$ in each case. But upon what basis may I then affirm that $\mathrm{p}$ is like $\mathrm{r}$ (in the sense of what it is like to experience)? Here it seems that we must appeal to a prior experiential knowledge of $r$ and in consequence, we are compelled to admit that $r$ must be knowable first and foremost in relation to itself and only secondarily in relation to $\mathrm{p}$. So supposition of the separate instantiation of phenomenal properties results in a contradiction and likewise leaves the basis of our knowledge of even representational properties open to question.

\section{The Redundancy Argument}

There is then a second difficulty. We suppose, as anti-materialists, that a phenomenal property $\mathrm{p}$ is instantiated within consciousness in relation to some representational property $r$. In consequence, experience necessarily entails two distinct kinds of content, an intentional content $\mathrm{R}$ in relation $\mathrm{r}$ and $\mathrm{a}$ phenomenal content $\mathrm{P}$ in relation to $\mathrm{p}$. But since $\mathrm{P}$ also expresses what $\mathrm{R}$ is like, then $\mathrm{P}$ must include $\mathrm{R}$ with the addition of some difference, say *, so that we might in turn express the phenomenal content $\mathrm{P}$ as $\mathrm{R}^{*}$. From this it follows that the phenomenal content $\mathrm{R}^{*}$ is distinct from $\mathrm{R}$ on the basis of an added content * that is anything but $\mathrm{R}$. In other words, consciousness of say, what red is like, differs from the representation of red on the basis of a content and difference that is, at bottom, anything but red.

\section{Argument From the Unnecessary Duplication of Experience}

Supposing that, as representationalists, we reject the view that phenomenal properties involve instantiation of a separate phenomenal content over and above the intentional content of experience, while upholding the phenomenal character of experience. In consequence, a phenomenal property $\mathrm{p}$ would be the result of the way in which the intentional content $\mathrm{R}$ is represented. So then the way in which $\mathrm{p}$ is represented must itself be some form of content-bearing experience. For any identifiable content must be translatable into an experience of that content. But $\mathrm{p}$ is an identifiable content pertaining to the way experience is represented. So $\mathrm{p}$ is a content-bearing experience. This in turn implies that every represented property $r$ includes both an intentional content $\mathrm{R}$ coupled with an added experiential content $\mathrm{D}$ in relation to the way $\mathrm{p}$ is represented. In consequence, it would appear that the representationalist position leads to an unnecessary duplication of 
experience. For to every R for which there is some $\mathrm{p}$, we may assert the added content-bearing experience of $\mathrm{D}$. We are in turn compelled to inquire into the relationship, in content, between $\mathrm{D}$ and $\mathrm{R}$, and in consequence, we inevitably face the redundancy argument. Addendum: We might of course object that the way a property is represented is not an experiential content, but is instead a feature of representational consciousness itself. But unless that feature stand over and above representational experience, it must in each case be reducible to some added content for our experience, for otherwise, how could we know of it?

\section{Observations}

If we accept the results of the above three arguments, at least tentatively, then we are compelled to conclude that phenomenal properties lack content and alternatively that experience apart from consciousness of experience is insufficient to account for the nature of phenomenal properties and in turn phenomenal character. We are therefore faced with a dilemma. On the one hand, we deny anything positive to the content of phenomenal properties, and on the other hand, we uphold the view that the phenomenal character of experience is the result of the addition of consciousness over and above experience which in turn includes the notion of phenomenal properties insofar as phenomenal character implies consciousness of what the experience of any representational property is like. This dilemma inevitably points to a third possibility and so to our own argument and solution, viz., that phenomenal properties are contentless modes of appearances within consciousness of the experience of representational properties.

\section{Reference to I}

Now a principal characterization of the phenomenal character of experience is undoubtedly the fact that such experience arises according to the first-person perspective of the "I" and ego for whom there is said to be an experience. ${ }^{3}$ This is evident from the fact that in the everyday consideration of our experience, we do not say, "There was an experience of $x$ ", but instead, "I experienced x". Still more, the reference to I is inherently immune to error through misidentification (Shoemaker 1968). I could never be mistaken regarding the reference of my experience to myself, nor mistake the experience of another for my own. Still more, far from implying that I am a conscious observer in the sense of a detached spectator viewing experience from afar within the theater of consciousness (Dennett 1991), the reference to I likewise includes the immersion of the observer within the undergoing of this experience. As both observer and as one who undergoes experience as the observer of it, I am in consequence the referential focal point of the relationship between consciousness and the conscious observation of experience. Experience is referred to $m e$ as observed and alternatively I refer experience to myself as the conscious observer of my experience.

\footnotetext{
3 "One generally agreed upon fact about phenomenal states is that they are perspectivally subjective...knowing what it is like to feel pain requires one to have a certain experiential point of view or perspective, namely the one conferred upon one by being the subject of pain.” (Tye 1999, 706)
} 
The observation of experience is further determined according to the specific restriction that it take place here now. This implies that all other determinations of observed experience find always some reference to I as the here and now observer of that experience. In consequence, I here and now perceive, sense, judge, assume, hope for and likewise expect and recollect. This last determination is of particular interest insofar as it reveals the way in which we refer temporal experience to our here and now consideration of it. For example, I might recall an experience from the past. In so doing, I bring to mind some past experience. As is evident, the act of recollection itself takes place according to my present observing act of recollection. For this reason, in recalling any past experience, I refer the past-now to my present-now in such a way that the former is called then in reference to the now of the latter. Alternatively, I might speak of the spatial locality of an object in the room, e.g., the lamp on the other side of my desk. In doing so, I refer it to my here and now observation and so say that the lamp is there now. Later on, I may speak of the lamp and in this case, I again refer the experience of it to my here and now consideration and so speak of the lamp as there before. Such spatiotemporal indicators are essential to the human experience and likewise serve to reveal that fact that every observed experience in each case finds its focal point according to the reference to I.

Even as the observer is restricted to the here and now observation of experience, the observer need not be restricted to the immediate "pre-reflective" undergoing of this experience. To the contrary, we may at any moment redirect our observing I and reflect upon the pre-reflective immediacy of our experience as though one step removed from it. So by "reflection" I mean the higher-order act of observing my own consciousness and the experience of consciousness. ${ }^{4}$ Reflection is in turn a derivative state of consciousness that follows upon the more primordial pre-reflective state of consciousness where the observer is immersed within the immediate undergoing of experience. To offer a simple example, we might consider an experience of being frightened, for instance, believing we are in a room alone only to be suddenly tapped upon the shoulder, and distinguish this from the consideration that follows afterward of what the experience of fear was like. In the first instance, even as we are caught within the pre-reflective immediacy of feeling fear, we are observers of our experience. On the other hand, when we later reflect

${ }^{4}$ For example, in his Language, Thoughts and Consciousness (1996, pp. 154-155), Peter Carruthers states, "Even if knowing what an experience is like is a special sort of capacity...still it is a capacity which will involve the ability to recognise, to imagine, and to remember a given type of experience, all of which presuppose a capacity for reflective self-awareness. In order to be able to recognise a pain, you have to be capable of knowing that you are in pain, when you are; and similarly for imagination and memory. So the conclusion is established: in order to know what an experience is like, you have to be capable of higher-order awareness of the occurrence of that experience." So too, in The Transcendence of the Ego (1960, pp. 40-41), Jean-Paul Sartre states of pre-reflective consciousness, "We should add that this consciousness of consciousness-except in the case of reflective consciousness which we shall dwell on later-is not positional, which is to say that consciousness is not for itself its own object. Its object is by nature outside of it, and that is why consciousness posits and grasps the object in the same act. Consciousness knows itself only as absolute inwardness. We shall call such a consciousness: consciousness in the first degree, or unreflected consciousness." For further discussion of this distinction, see Zahavi (2008). 
upon this experience, we are no longer observers in the same sense. Indeed, we do not observe from within the undergoing of fear but now as outside observers of that undergoing. This is then what is here understood with respect to the distinction between pre-reflective and reflective consciousness. According to the former, we observe within the immediacy of experience. According to the latter, we observe as though one step removed from it. ${ }^{5}$

Within pre-reflective consciousness the reference to I is only implicit, which is to say, a relationship between observer and observed holds for pre-reflective consciousness, but we do not explicitly recognize this relationship. At best, we only know that "I experience x". Following upon the reflective consideration of our experience, however, we quickly discover that there is an experience of $\mathrm{x}$ only insofar as we are the conscious observers of $\mathrm{x}$. In consequence, through reflection, the reference to I now stands forth explicitly (i.e., as an objectifying relation) and in such a way that a distinction may then be drawn between the conscious observer and experience as observed.

\section{The Nominative, Dative and Genitive Modes}

So in everyday pre-reflective consciousness, whether walking, talking, eating, thinking, etc., the observer is in each case immersed within the undergoing of an experience. We interact with the world and the objects of our experience without any explicit re-cognition of the way in which such experience arises and so apart from any direct consideration of the part that we play as observers of this experience. In a way, we forget that we are actors within the play of experience and instead simply play the role of working, thinking, feeling, sensing, wondering, wanting and so on. At other times, however, we do indeed depart from the prereflective immediacy of experience into reflective consideration of it. We now view our own consciousness and the experience of consciousness one step removed from it. We clearly see our own act of observation as it occurs. We recognize the relationship between this observing act, the corresponding observation of experience and we likewise recognize the reference to I with respect to both.

For the sake of argument, let us presume ourselves to now adopt this higher standpoint of reflection. Let us cease to be immersed within the pre-reflective immediacy of experience and instead consider experience one step removed from it. What is brought forth from this higher standpoint is then the following: Where before we recognized, if but obscurely, that within the pre-reflective immediacy of experience "I experience x", we now discover the precise nature and relationship between I and x. From the reflective standpoint, we discover that the observer is the very condition for the recognition of $\mathrm{x}$. This we

\footnotetext{
${ }^{5}$ Of course, observation implies awareness as well as self-awareness. From this we might initially conclude that observation and awareness are one and the same. There is, however, an important difference. By awareness is in general meant the abiding recognition of one's own consciousness (pre-reflective or reflective) that is carried along with and accompanies experience. On the other hand, observation includes within itself awareness and further implies a relationship between the observer and the observed. In other words, whereas awareness refers to a feature of the observer itself within consciousness, observation refers to a relationship between the observer and the observed.
} 
determine from the fact that we cannot speak of an observed experience apart from the observation of it. Of course, this need not imply that I am always at this moment observing every experience within consciousness, but only that, in order to speak of the phenomenal character of experience, of what it is like to experience, which is here our primary concern, it is necessary that experience be in some sense observed by me.

If we further examine the nature of our experience according to the various ways in which the observer relates to experience as observed, we discover three distinct modifications of it. These three modifications correspond to three reflective standpoints taken with respect to the observer and the observed within experience. Again, it is important to note that within pre-reflective consciousness although the relationship between the observer and the observed holds, that relation is known to us at best implicitly. Through reflection, this relationship is then brought forth explicitly (as an object) for our knowledge.

Turning to the three modifications of experience, there is first the "nominative mode" as a result of reflective recognition upon the whole relation that holds between the observer and the observed according to the reference to I. With respect to this modification, experience is now qualified with the addition that it is an experience of the observer, and in consequence we say:

$$
\text { I observe x. }{ }^{6}
$$

So we can never speak of what an experience is like apart from the observation of it, and insofar as we do, we immediately assert a relationship, through I, between experience as observed and the conscious observer of it. The relationship is absolutely primitive. Apart from the reference to I we simply cannot speak of the observation of experience. The nominative mode in turn presents the simple and undeniable modification of the conscious observer as an essential condition inherent in consciousness of what it is like to experience.

Following the nominative mode, we have two further modes. These two additional modes pertain to the relationship between the observer and the observed according as we consider each respective side of that relation. So in the first place, there is the relative side of experience as observed. From this standpoint, experience is viewed according to the modification of being to and for me as an observer of it. It is important to understand both how and why this occurs. Within pre-reflective consciousness, we are caught within the immediacy of our experience. From this standpoint, we know only that "I experience x". On the other hand, through reflection, the reference to I of experience immediately stands forth so that experience is now modified according to the addition that, "I observe x". This observation of $\mathrm{x}$ may then be considered according to each respective side. From the side of experience as observed, the experience of $\mathrm{x}$ is now viewed according to the reference of being to and for me as the observer of it. In effect, I now reflectively view my own observed experience with an added vector, where I, as the observer, serve as the focal point toward which that vector is directed. The determination of the direction of the vector is likewise asserted on

\footnotetext{
${ }^{6}$ The addition that the observation take place "here now" is understood and left unstated.
} 
the basis of the reference to I. Experience is then viewed according to the modification of being directed toward me and for me. This particular modification of experience I call the "dative mode", which is further expressed as follows:

$$
\mathrm{x} \text { is given to me (as observed). }{ }^{7}
$$

The dative mode is essentially receptive in character, akin to reaching out to take a gift that another offers to us. Through the dative mode, we discover the fact that experience is given and in consequence, experience is recognized as both distinct from and yet related to I as the observer. So the dative mode serves in some sense as the very basis for recognition of the distinction between subject and object, self and other, etc., insofar as that which is given does not yet belong to me and so is not yet properly my own. This last point will be further considered following examination of the third mode.

There is then a third and final modification according to the relative side of the observer. According to this third mode, I now view the reference to I from the perspective of myself as observer. In consequence, I refer the observation of experience to myself as the observer of it. This in turn leads to the recognition that the observed experience is my own. Still more, whereas through the dative mode, the observer and observed are divided, according to the third mode, that division in some sense collapses into an indistinguishable unity. What is now recognized is that as the observer of experience, I am the one for whom there is said to be an experience. I am accordingly not only an observer of an experience that is other to me, that is then referred back to me; but alternatively, I refer experience to myself in such a way that I become the possessor of it. Insofar as the observation of experience now belongs to me, the distinction between the observer and the observed thereby collapses into one another. This third mode is in consequence appropriative. By way of analogy to the dative, we might say that the object that was offered to me as a gift I now claim as my own. We have likewise a transition from reception to appropriation, and as appropriation implies both ownership and possession, to that extent I call this third mode the genitive mode, expressed as follows:

$$
\mathrm{x} \text { is my own (as observer). }
$$

So from the standpoint of the genitive mode, experience obtains the appropriative modification of

\footnotetext{
${ }^{7}$ For further discussion of the role of referential indicators such as I, he, they, etc., see Castaneda (1966 \& 1967), Bermudez (1998) and more recently, Hank (2013). It is worth noting that most discussions of such indicators in relation to consciousness tend to center around the nominative "I", whereas less emphasis in general is focused upon the dative "to/for me" and genitive "my own/mine" structures here developed. We do find some initial inquiry, however, into the concept of "me-ishness" in Block (1995).
} 
possession and ownership, which is to say of being mine and $m y$ own ${ }^{8}$ Indeed, as observed, experience is undeniably my own, and this determination arises prior to any further modification with respect to the objects of my experience, including my own body. For even though my body is certainly the most proximate (closest and most intimate) possession, we nonetheless experience the body as a datum. So I can view my hands and legs as objects other to me and for me (according to the dative mode) and even to some extent the inner sensations of pain and pleasure insofar as they each arise objectively as data within experience. For this reason, although the body is the most proximate possession, the body is not the foundation of the recognition of ownership. Rather, the principle of ownership is rooted in the reference to I according to the genitive mode of appropriation. Secondarily, the body serves as the most proximate appropriation that follows from this mode. Finally, through the body, we refer possessively to other objects encountered within the world of our experience.

As a further point, it is worth noting that we cannot reduce experience to the objectivity of its dative modification, but instead, a complete account requires that we include in each case what is genitive within it. Thus experience is not only something that happens over and above me as a datum that I might study. Rather, I also undergo and abide within my experience as the subjective possessor of it (for which reason the conscious observer is often referred to as a "subject" of experience). This can readily be seen through consideration of pain experience. As is well known, cognitive scientists make use of pain reports derived from experiencing subjects themselves (Chapman et al. 2002) and from this attempt to causally model pain in such a way that it appears that we might now exclude the subjective foundation inherent in pain experience from any such model. But if we examine pain experience more fully, we find that such models fall far short of offering an adequate account of the nature of pain inasmuch as they omit the primary way in which we experience pain, which is at bottom genitive. ${ }^{9}$

For example, I might light a flame and hold my hand close to it. At first, I observe only heat and perhaps a dull sensation of discomfort. At this point, I might likewise attempt to reflect upon this experience and consider this discomfort in its dative modification (as given) only. But as I further draw my hand closer to the flame, something happens. The intensity of this discomfort increases until it is transformed into a raw and vigorous experience of pain. Pain now appears inwardly and aggressively and the closer and longer that I hold my hand over the flame, the more unbearable it becomes up unto the point that, no longer able to withstand the experience of pain, in an abrupt motion, I remove my hand away from the flame.

Two important points may be drawn from this example. First, as pain increases, we note that the ability to stand apart and reflect upon our experience quickly recedes into the distance, so that pain

\footnotetext{
${ }^{8}$ The genitive mode is the definitive mode expressed by Martin Heidegger within his Sein und Zeit in relation to Dasein, viz., "We are ourselves the entities to be analyzed. The Being of any such entity is in each case mine." (Heidegger 2001, 42)

${ }^{9}$ Among such approaches, however, there is some tacit admission of the role of phenomenal experience in at least the recognition and production of our subjective reports about pain (Nakamura et al. 2002).
} 
inevitably draws us into the pre-reflective immediacy of experience. Excepting the most intrepid of souls, no reflection upon the experience of pain occurs within the throes of intense pain inasmuch as I simply cannot just stand upon the sidelines, as it were, and simply watch pain, but I am instead forced to reckon with my pain. At the same time, when the pain ceases to be, we may return to it through an act of reflective recollection. In so doing, as we consider the moment in which pain was at its most unbearable, we realize that the distinction between observer and observed was in some sense lost entirely within the experience and what remained was just a being in the possession and being possessed by pain, as though the observer and observed mutually swallowed up one another akin to a great Ouroboros swallowing its own tail.

So within everyday experience, the relationship between observer and observed is in a way harmonized so that the nominative mode is also the "normative" mode of experience. We go about our day relating to observed objects normally, perceiving, thinking, desiring and so on. On the other hand, certain encounters, pain serving as a primary example, draw out the other modifications of experience from within the pre-reflective state of consciousness, to such an extent that either the dative or genitive mode is emphasized. For this reason, we experience intense pain as though entirely consumed by it, as though we have swallowed it and it has swallowed us. But what we here experience, as determined afterward through reflecting upon it, was in fact a distinct modification of our experience. In other words, we experienced pain genitively, as a possession that we then refer to ourselves as our own.

As it is, the above example and the genitive nature of pain serves to confirm the fact that there are features of consciousness that are simply intractable to the methods of objective scientific scrutiny pointing to an explanatory gap (Levine 1983) with respect to the study of consciousness. As is evident from the explanations here given, the primary basis for this explanatory gap involves the various ways (modifications) in which the observer is said to be conscious of experience. Indeed, we cannot study these ways apart from the inner observation of them. In the attempt to omit the observer, which is to say, to omit the phenomenal and quite subjective character of experience, we end up tearing out the very roots according to which such experience is known to us.

For a further and final point, we might consider an experience where the dative mode is in this case emphasized. For example, we might feel sympathetic in relation to the grief that a friend experiences over the death of a loved one. In the first place, the feeling of sympathy involves a state of belief that the other is in grief and second, this belief is coupled with a state of emotive feeling. In the state of sympathy, we feel the pain of the other, but as the hand that is held neither too close nor too far from the flame, we keep the feeling of pain at a distance. In relating to that other, we do so from the standpoint of pre-reflective immediacy of experience. That is not to say that we cannot at this moment reflect upon our sympathy, but in so doing, we depart from the underlying immediacy and, in a way, cease to be sympathetic. On the other hand, if we do so afterward, if we later reflect upon that feeling, we realize that sympathy is itself an experience modified according to emphasis upon the dative mode that is nonetheless coupled to the genitive. Furthermore, as we feel sympathy, the object of sympathy is no longer something that I just observe in the sense of indifferently looking at. Rather, the grieving person is now seen in the dative 
relation as an "Other" that is given to me. I in turn receive the other, coupled with their grief, and in consequence feel sympathetic. Within sympathy, there is therefore a greater pull in terms of the dative, insofar as belief (i.e., that the other is in fact grieving and not dissembling grief) serves as the primary motivation for that feeling. That pull is further grounded, however, within the genitive pain (in an emotive sense) that accompanies it, but again, such pain is kept at a bare minimum.

In consequence, with sympathy, I do not appropriate the grief of the other. To the contrary, I keep genitive appropriation at a distance and stand within emphasis upon the dative reception of belief and the pain of the other as a given object. If I proceed further to then appropriate this grief, as it were, to really feel and possess the pain of the other, I then exchange my state of sympathy for a new state of empathy and this in turn translates into emphasis first upon the dative mode of reception (receiving grief sympathetically) into the genitive mode of appropriation (appropriating grief empathetically).

\section{Phenomenal Properties as the Shadows of Consciousness}

Following analysis of above three modes of experience, we now turn to an account of the nature and distinction between representational and phenomenal properties. In the first place, representational properties pertain to the pre-reflective immersion of the observer within experience according to which there is experience of some intentional content. Accordingly, we might speak of the experience of some visual-content from which we obtain the representational property $\mathrm{r}$, as the perception of red. Now phenomenal properties express the phenomenal character inherent in what the experience of some representational property is like. In the above example, we would then speak of the phenomenal property $\mathrm{p}$, pertaining to consciousness of what the experience of $r$ is like.

According to the view taken here, phenomenal properties are not per se distinct from representational properties nor are they the same. Alternatively, phenomenal properties cannot be reduced to representational experience. The reason for this has to do with the fact that consciousness appears to add something quite specific, and the problem and basis for much of the difficulties centered round discussion of the nature of phenomenal properties, has to do with the fact that while consciousness adds something, it adds nothing to the specific content of experience itself. Instead, phenomenal properties are the result of the way in which the observer observes experience.

For this reason, we understand and speak of phenomenal properties as "contentless modes of appearances" of our experience of representational properties. So a phenomenal property is an appearance in the sense of a modified presentation of the experience of some representational property according to the reference to I of the conscious observer. Such properties are contentless inasmuch as, in and of themselves, they do not add anything to the content of our experience. As we have seen, there are three modifications, viz., nominative, dative and genitive. These modifications are intertwined from the perspective of the prereflective immediacy of experience. Still more, the distinction between these modes cannot be known explicitly from within the pre-reflective state but only following upon an act of reflection. For this reason, 
according to our view, pre-reflective consciousness involves an experiential undergoing of intentional content and does not yet include the phenomenal. On the other hand, through reflection, we obtain explicit access to these modes according to another sense, which is to say, according to the higher-order reflective observation of what it is like to experience pre-reflectively. We then form a phenomenal identity with respect to the immediate pre-reflective experience of some property coupled with a re-consideration of the ways in which that same property is then referred to I through reflective observation of it. In general, it is this identity within and through reflective observation that gives us the sense of what it is like to experience. For through such an identity, the same experienced property is related to itself according to different modifications of our experience of it. What results from this is at best an apparent property, which is in turn called phenomenal.

Having stated our solution to the problem of phenomenal properties generally, we turn now to a more specific explanation of that solution. In the first place, we here understand the phenomenal property to be the result of a phenomenal identity, but it is important to further understand the precise nature of this. To illustrate, we consider a subject $\mathrm{S}$, blind from birth who, following surgery, is able to see for the first time. After acclimating to the this new condition, $\mathrm{S}$ is asked to answer the question, "What is the experience of red like?" The task is to offer an explanation of the phenomenal property inherent in consciousness of what the experience of the representational property red is like.

If we examine the possible answers that might be given, we find two interesting and diverse points of view. Although we admittedly cannot predict with accuracy the specific details of S's description of what the experience of red is like, we can nonetheless identify the type of description that ought to be given. The question inquires into what the experience was like, and in turn establishes the requirement that $\mathrm{S}$ respond through the use of some form of comparative example (whether analogy, simile, metaphor, and so on). In effect, the proper response to the question ought to then take on the following exemplary form- " $\mathrm{x}$ is like y”. So we might imagine the description offered by $\mathrm{S}$ to be along the following lines:

"Prior to my operation, I used to imagine what the experience of color might be like. In so doing, I would often make use of the description of others coupled with my other senses as a basis for comparison. In particular, since color, I was told, involves contrariety between black and white and as I supposed that the nothing that I "saw" while blind was akin to black, I supposed that white would then represent a certain fullness with respect to its opposite. Alternatively, in the sensation of heat, I noticed that in extremely cold weather my fingers and toes would become numb so that I thought of cold as "empty" akin to the color black. Alternatively, heat fills the emptiness of the cold and brings back sensation and there are degrees to heat from the lukewarm to the hot to the scalding. In turn, I imagined that the most extreme heat would be something like white as the opposite of black, and between the extremes of hot and cold I then imagined all the colors would therein find a place. Following my operation, however, I now realize that although there is indeed a similarity of proportion between the various colors and the various sensations of hot and cold, the actual experience of red and indeed any other color for that matter is quite unlike anything I could have 
ever possibly imagined. Indeed, there is nothing it is like to experience red apart from the experience red, so that what it is like to experience red is more akin to what it is like to encounter something or someone unknown to us for the first time. Still more, the thing or person is not the same as the encounter of that thing or person and this implies that the encounter itself is not nothing, but instead relates to the fact that there is someone for whom there is said to be an encounter. So to answer your question, I would say that what it is like to experience red is like the experience of red coupled with the fact that red is something that I encounter in the sense of a first introduction."

So what we here discover is that prior to experiencing red, $\mathrm{S}$ attempts to imagine what it is like to experience red through drawing a comparison between one representational property (red) and another representational property (a degree of heat) of an entirely different kind. Following the experience of red, however, $\mathrm{S}$ realizes that although the comparison was adequate in one sense it was inadequate in another. Indeed, it was adequate as a proportion but inadequate insofar as the actual experience of red includes the addition that red is an encounter for $\mathrm{S}$, akin to being introduced to someone or something for the first time. There is thus something about the experiential encounter with red that holds over and above any knowledge that $\mathrm{S}$ could have prior to that encounter.

If we further understand reflection to involve, in a way, a constant re-introduction of our experience to ourselves, according as I now stand one step removed from my experience and reflect upon the reference to I within it, then we appear to have determined the very foundation of the phenomenal character of what it is like to experience. Indeed, every experienced representational property is known first and foremost within and through the pre-reflective immediacy of experience. Through reflection, we re-introduce experience to ourselves so that the observer and the observed now stand forth as an experiential encounter in their mutual reference to I. From the reflective standpoint, a comparison is then formed, a phenomenal identity, for the representational content and its encounter within and through reflective consideration of it. This encounter may likewise occur according to three modifications. So according to the nominative mode, we identify a relationship between consciousness and experience through I. According to the dative mode, experience is given to and for me. According finally to the genitive mode, as the observer of experience, I now recognize that experience is in some sense my own.

We are accordingly in a position to determine the foundation of the relationship between representational and phenomenal properties. In the first place, in contradistinction to the representationalist position, we conclude that phenomenal properties are not the result of the way in which the intentional content of experience is represented, but instead are the result of the way in which we are conscious of our experience. Phenomenal properties are founded upon a comparison and indeed a phenomenal identity formed with respect to the pre-reflective immediacy of experience, according to which we first undergo an experienced property, coupled with reflection upon that experience from which there is now re-cognition of the experiential encounter with respect to the observer and the observed in their mutual reference to I. In effect, for any representational property $r$ and phenomenal property $p$, we obtain the following: 
And alternatively,

$$
\begin{array}{llll}
\text { I observe } \mathrm{r} . & = & \mathrm{p} \text {-nominative } & \\
\mathrm{r} \text { is given to me. } & = & \mathrm{p} \text {-dative } & \text { \{Reflective consciousness } \\
\mathrm{r} \text { is my own. } & = & \mathrm{p} \text {-genitive }
\end{array}
$$

We have in each case one and the same representational property according to three distinct modifications of the observation of our experience of it, thereby yielding the appearance of that property, which is then what we understand to be a phenomenal property. Finally, we say that the observation, reception and appropriation of the representational property is what it is like to experience that property, and in general:

$$
\mathrm{p} \text { is like } \mathrm{r} \text {. }
$$

As is evident from the above, in contradistinction to the anti-materialist position, the phenomenal property $\mathrm{p}$ is not at all distinct in content from the representational property $\mathrm{r}$ but is a result of the relation that holds between the pre-reflective experience of some representational property and its reflective re-consideration within consciousness. We may in turn conclude that phenomenal properties are the result of the form of consciousness, which is to say, the reference to I of the conscious observer and observed experience. Indeed, phenomenal properties are contentless shadows of consciousness. Akin to the shadows of perceptible experience which, while devoid of content, yet retain the form and figure of the bodies of which they are the shadow, so too phenomenal properties retain the form of the peculiar modification of the matter of the content of an experienced representational property, according to the various relations that hold with respect to the conscious observer and the observation of experience.

We have accordingly identified what a phenomenal property is, and so resolved or at least shed some further light upon the problem of phenomenal properties. As is evident from our solution, the phenomenal character of consciousness, akin to phenomenal properties, must likewise be the result of the relationship that holds between the conscious observer and observed experience according to the reference to I. We therefore speak of the phenomenal character of experience on account of the fact that through reflective observation upon pre-reflective experience, the various modifications of experience in relation to the observer now stand forth phenomenally as an encounter for the observer. Following this, by way of comparison and phenomenal identity, we accordingly speak of what it is like to experience.

\section{REFERENCES}


Bermudez, J.L. (1998). The Paradox of Self-Consciousness (Representation and Mind). Cambridge MA: MIT Press.

Block, N. (1995). On a Confusion About a Function of Consciousness. Behavioral and Brain Sciences, 18: $227-87$

Carruthers, P. (1996). Language, Thoughts, and Consciousness: An Essay in Philosophical Psychology. Cambridge: Cambridge University Press.

Castaneda, H. (1966). 'He': A Study in the Logic of Self-Consciousness. Ratio 8: (130-57).

Castaneda, H. (1967). Indicators and Quasi-Indicators. American Philosophical Quarterly, 4(2): 85-100.

Chalmers, D. (1995). Facing Up To the Problem of Consciousness. Journal of Consciousness Studies, 2: 200-219.

Chalmers, D. (2004). The Representational Character of Experience. The Future for Philosophy, B. Leiter (ed.), Oxford: Oxford University Press.

Chapman, C., Donaldson, G.W., Nakamura, Y., Jacobson, R.C., Bradshaw D.H., Garvin, J. (2002). A Psychological causal model of pain report validity. The Journal of Pain, 3(2): 143-55.

Dennett, D. (1991). Consciousness Explained. Boston: Little, Brown and Company.

Dretske, F. (1995). Naturalizing the Mind. Cambridge, MA: MIT Press.

Hank, P. (2013). First Person Propositions. Philosophy and Phenomenological Research, 86(1): 155-82.

Heidegger, M. (2001). Sein und Zeit. Tübingen: Max Niemeyer. Tran. J. Macquarrie \& E. Robinson, Oxford: Basil Blackwell (2004).

Levine, J. (1983). Materialism and Qualia: The Explanatory Gap. Pacific Philosophical Quarterly, 64: $354-61$.

Levine, J. (2001). Purple Haze: The Puzzle of Consciousness. New York: Oxford University Press.

Lycan, W. (1996). Consciousness and Experience. Cambridge, MA: MIT Press.

Nagel, T. (1974). What is it like to be a Bat?. Philosophical Review, 83: 435-56.

Nakamura, Y., Chapman, C.R. (2002). Measuring pain: An introspective look at introspection. Consciousness and Cognition, 11: 582-92

Sartre, J. P. (1960). The Transcendence of the Ego: An Existentialist Theory of Consciousness. Tran. Williams, F., Kirkpatrick, R. New York: Hill and Wang.

Shoemaker, S. (1968). Self-Reference and Self-Awareness. Journal of Philosophy, 65(19): 555-67.

Tye, M. (1995). Ten Problems of Consciousness. Cambridge, MA: MIT Press. 
Tye, M. (1999). Phenomenal Consciousness: The Explanatory Gap as Cognitive Illusion. Mind, 108: 70525.

Zahavi, D. (2008). Subjectivity and Selfhood: Investigating the First-Person Perspective. Cambridge, MA: MIT Press. 